УДК 66.011

\author{
ОПТИМИЗАЦИЯ ПРОЦЕССА РЕКТИФИКАЦИИ \\ ГИДРОГЕНИЗАТА НА КОМПЛЕКСЕ ПРОИЗВОДСТВА \\ АРОМАТИЧЕСКИХ УГЛЕВОДОРОДОВ
}

\title{
OPTIMIZATION OF HYDROGENIZATE RECTIFICATION PROCESS AT THE AROMATIC HYDROCARBON PRODUCTION COMPLEX
}

\author{
М. Р. Юсупов, А.В. Ганцев \\ Уфимский государственный нефтяной технический университет, \\ г. Уфа, Российская Федерация \\ Marsel R. Yusupov, Alexander V. Gantsev \\ Ufa State Petroleum Technological University, Ufa, Russian Federation \\ e-mail: marsel.yusupov.2014@mail.ru
}

Аннотация. В статье рассмотрена возможность оптимизации процесса ректификации гидрогенизата на комплексе производства ароматических углеводородов для уменьшения общих энергозатрат.

На сегодняшний день важнейшей задачей энергетики и экономики страны в целом является сокращение энергоемкости производства и широкого внедрения энергосберегающих технологий. Российские НПЗ стараются увеличить собственную энергоэффективность путем применения современных технологий, улучшения рекуперации тепла, увеличения КПД печей, модернизацией оборудования, переобвязкой и перенаправлением потоков.

Некоторые НПЗ включают в себя комплексы по производству ароматических углеводородов, построенных по типовому проекту компании UOP. Основой комплекса по производству ароматических углеводородов является установка каталитического риформинга, 
перерабатывающая в настоящее время гидроочищенную бензиновую фракцию (70-170 $\mathrm{C})$. Для выделения сырья определенного фракционного состава гидрогенизат направляется на установку ректификации бензинов (секция 100 КПА). Для разделения гидроочищенного бензина на фракции затрачивается большое количество энергии, которое можно уменьшить при оптимальной конфигурации установки.

В статье представлены результаты моделирования секции 100 КПА и возможные пути оптимизации процесса ректификации, позволяющие увеличить энергоэффективность установки в целом не снижая качество продуктов.

Abstract. The article discusses the possibility of optimizing the process of rectification of hydrotreated fractions at the complex for the production of aromatic hydrocarbons in the direction of reducing the total energy consumption.

Today, the most important task of the energy sector and the country's economy as a whole is to reduce the energy intensity of production and the widespread introduction of energy-saving technologies. Russian refineries are trying to increase their own energy efficiency by using modern technologies, improving heat recovery, increasing the efficiency of furnaces, modernizing equipment, repiping and redirecting flows.

Some refineries include complexes for the production of aromatic hydrocarbons, built according to the standard design of the UOP company. The basis of such a complex for the production of aromatic hydrocarbons is a catalytic reforming unit that processes narrow hydrotreated gasoline fractions $\left(70-170^{\circ} \mathrm{C}\right)$. To isolate raw materials of a certain fractional composition, the hydrogenated product is sent to the gasoline rectification unit (section $100 \mathrm{KPA}$ ). At the same time, a large amount of energy is spent to separate gasoline into fractions, which can be reduced with the optimal configuration of the unit.

The article presents the results of modeling the section $100 \mathrm{KPA}$ and possible ways to optimize the rectification process, which make it possible to increase the 
energy efficiency of the installation as a whole without reducing the quality of the products.

Ключевые слова: бензин; гидрогенизат; энергоэффективность; производство ароматических углеводородов; процесс ректификации; каталитический риформинг

Key words: petrol; hydrogenate; energy efficiency; production of aromatic hydrocarbons; rectification process; catalytic reforming

В современном мире наблюдается тенденция к сокращению парниковых газов путем уменьшения потребления топлива, использования «зелёной энергии» и водородной энергетики, модернизации производств и замены устаревшего оборудования для соответствия процессов экологическим нормам и стандартам. Стоит отметить, что одним из главных источников парниковых газов является нефтегазодобывающая промышленность, причем около половины потребления топливно-энергетических ресурсов приходится на нефтегазоперерабатывающую сферу. Таким образом, повышение энергоэффективности на НПЗ является экологически важной задачей, и для её достижения нефтеперерабатывающие компании идут путем применения современных технологий, улучшения рекуперации тепла, увеличения КПД печей, модернизацией оборудования, переобвязкой и перенаправлением потоков [1-4].

На некоторых НПЗ есть комплексы по производству ароматических углеводородов (КПА), предназначенные для переработки бензиновых фракций в бензол, орто- и параксилол. Перед тем как превратить бензиновые фракции в ароматический концентрат на установке каталитического риформинга, бензины гидроочищают и путем ректификации добиваются необходимого фракционного состава сырья риформинга $\left(70-170{ }^{\circ} \mathrm{C}\right)$. Установка ректификации бензинов (секция 100) представлена на рисунке 1. Из гидроочищенных бензинов выделяют 
изопентановую фракцию нк-62 ${ }^{\circ} \mathrm{C}, 62-70{ }^{\circ} \mathrm{C}$ (сырьё изомеризации), фракции 70-130 ${ }^{\circ} \mathrm{C}$ и $130-170{ }^{\circ} \mathrm{C}$ (сырье риформинга) и тяжелую бензиновую фракцию 170-кк. В зависимости от потребностей продуктов, фракция 130-170 ${ }^{\circ} \mathrm{C}$ направляется на риформинг бензинового профиля или совместно с фракцией 70-130 ${ }^{\circ} \mathrm{C}$ для получения ароматических углеводородов. Таким образом, процесс ректификации гидрогенизата важен для оптимального выхода ароматических углеводородов и товарного изомеризата [5-9]. Процесс каталитического риформинга находится в прямой зависимости от технологических параметров данной установки, но при этом для более четкого разделения фракций расходуется иногда неоправданно большое количество энергоресурсов. Поэтому важно оптимизировать соотношение требуемых энергетических затрат для процесса и выход товарных продуктов $[9,10]$.

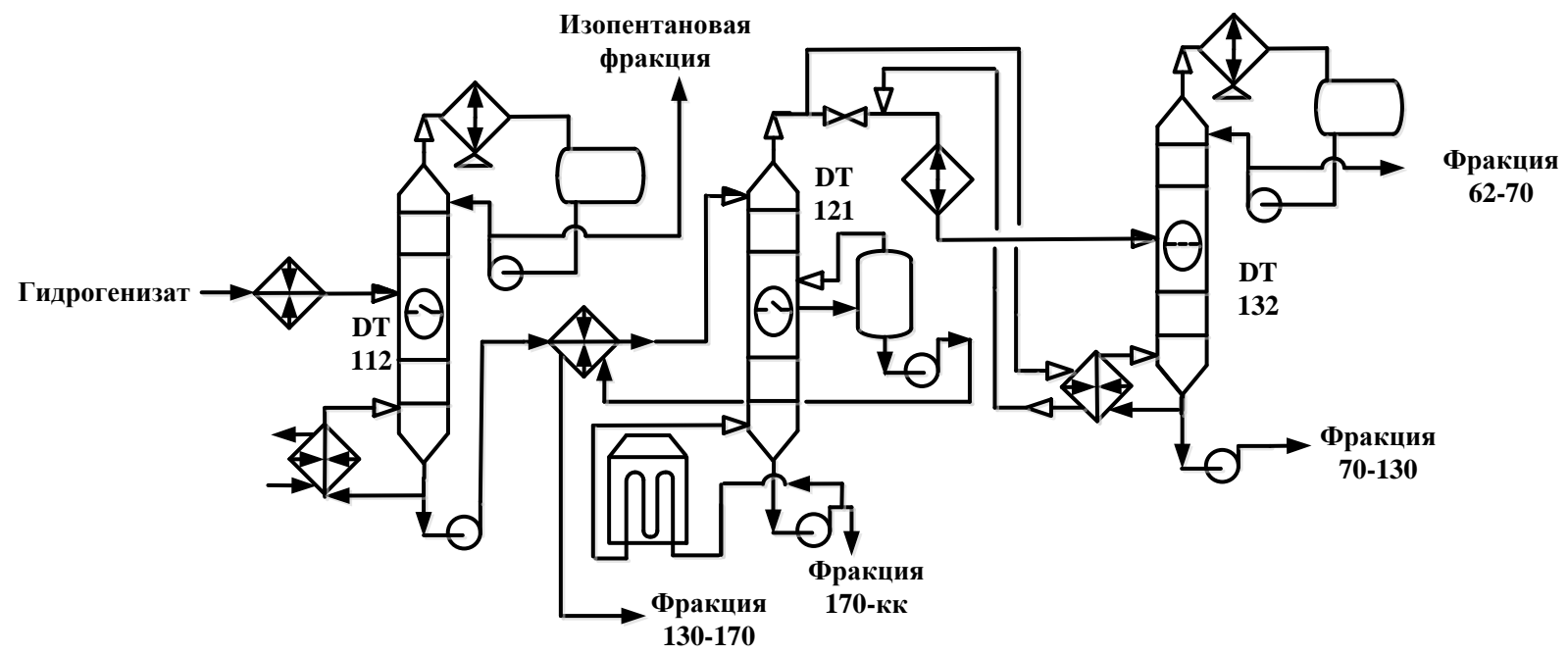

Рисунок 1. Технологическая схема секции 100 КПА

Оптимизацию процесса ректификации гидрогенизата путем создания математической модели в программном продукте Aspen Hysys.

Для создания более точной модели были проанализированы групповые углеводородные составы продуктов секции 100 на газовом хроматографе «Хроматэк-Кристалл 5000». 


\section{Результаты анализов представлены в таблице 1.}

Проанализированная фракция нк-62 ${ }^{\circ} \mathrm{C}$ содержит 3,66 \% масс. бутана, 0,25 \% масс. изобутана, 93,45 \% масс. изопентана, 2,64 \% пентана.

Таблица 1. Углеводородный состав продуктов секции 100, \% масс.

\begin{tabular}{|c|c|c|c|c|c|c|c|}
\hline 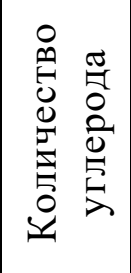 & 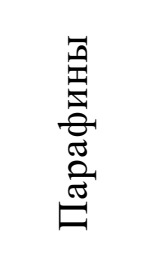 & 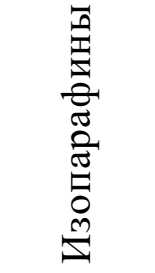 & 总 & 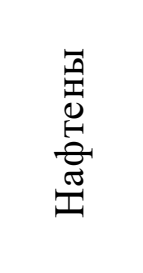 & 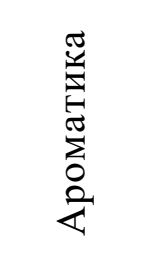 & 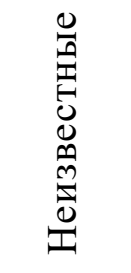 & $\begin{array}{l}0 \\
\text { O̦ } \\
0 \\
0\end{array}$ \\
\hline \multicolumn{8}{|c|}{ Фракция 62-70 } \\
\hline $\mathrm{C}_{5}$ & 28,1502 & 2,6107 & 0.0102 & 2,6649 & 0.0000 & 0.0000 & 33,4360 \\
\hline $\mathrm{C}_{6}$ & 22,3371 & 34,2233 & 0.0043 & 7,9689 & 1,9540 & 0.0000 & 66,4876 \\
\hline $\mathrm{C}_{7}$ & 0.0000 & 0.0727 & 0.0037 & 0.0000 & 0.0000 & 0.0000 & 0,0764 \\
\hline Всего & 50,4873 & 36,9067 & 0,0181 & 10,6338 & 1,9540 & 0,0000 & 100,00 \\
\hline \multicolumn{8}{|c|}{ Фракция 70-130C } \\
\hline $\mathrm{C}_{5}$ & 0.0006 & 0.0007 & 0.0000 & 0.0000 & 0.0000 & 0.0000 & 0.0013 \\
\hline $\mathrm{C}_{6}$ & 1,0019 & 0,0343 & 0,0005 & 5,4093 & 0,2765 & 0,0000 & 6,7225 \\
\hline $\mathrm{C}_{7}$ & 9,2119 & 11,2305 & 0,0008 & 11,1439 & 2,3908 & 0,0000 & 33,9779 \\
\hline $\mathrm{C}_{8}$ & 7,3626 & 9,7713 & 0,0000 & 11,4036 & 3,4861 & 0,0000 & 32,0236 \\
\hline $\mathrm{C}_{9}$ & 4,2300 & 6,9592 & 0,0232 & 6,2884 & 1,8997 & 0,0000 & 19,4005 \\
\hline $\mathrm{C}_{10}$ & 0,9175 & 2,8014 & 0,0000 & 1,5462 & 0,5787 & 0,0000 & 5,8438 \\
\hline $\mathrm{C}_{11}$ & 0,1258 & 0,4476 & 0,0034 & 0,2875 & 0,0782 & 0,0000 & 0,9425 \\
\hline $\mathrm{C}_{12}$ & 0,0134 & 0,0108 & 0,0000 & 0,0000 & 0,0396 & 0,0000 & 0,0638 \\
\hline $\mathrm{C}_{13}$ & 0,0134 & 0,0000 & 0,0017 & 0,0000 & 0,0194 & 0,0000 & 0,0345 \\
\hline $\mathrm{C}_{14}$ & 0,0000 & 0,0000 & 0,0000 & 0,0000 & 0,1864 & 0,0000 & 0,1864 \\
\hline Всего & 22,8771 & 31,2558 & 0,0296 & 36,0789 & 8,9555 & 0,0000 & 99,1968 \\
\hline \multicolumn{8}{|c|}{ Фракция 130-170 $\mathrm{C}$} \\
\hline $\mathrm{C}_{5}$ & 0.0000 & 0.0017 & 0.0000 & 0.0000 & 0.0000 & 0.0000 & 0.0017 \\
\hline $\mathrm{C}_{6}$ & 0.0000 & 0,0015 & 0.0000 & 0.0000 & 0.0026 & 0.0000 & 0.0041 \\
\hline $\mathrm{C}_{7}$ & 0.0000 & 0.0000 & 0.0000 & 0.0015 & 0.0016 & 0.0000 & 0.0031 \\
\hline $\mathrm{C}_{8}$ & 0,0971 & 0,0246 & 0,0000 & 0,5465 & 0,3692 & 0,0000 & 1,0375 \\
\hline $\mathrm{C}_{9}$ & 4,3985 & 1,7376 & 0,0000 & 7,9853 & 11,3418 & 0,0000 & 25,4633 \\
\hline $\mathrm{C}_{10}$ & 16,5368 & 20,6204 & 0,0000 & 16,5396 & 7,8402 & 0,0000 & 61,5371 \\
\hline $\mathrm{C}_{11}$ & 0,9408 & 7,2275 & 0,0389 & 3,1239 & 0,3285 & 0,0000 & 11,6596 \\
\hline $\mathrm{C}_{12}$ & 0,0839 & 0,0938 & 0,0021 & 0,0000 & 0,0938 & 0,0000 & 0,2736 \\
\hline $\mathrm{C}_{13}$ & 0,0100 & 0,0000 & 0,0000 & 0,0000 & 0,0039 & 0,0000 & 0,0139 \\
\hline $\mathrm{C}_{14}$ & 0,0027 & 0,0000 & 0,0000 & 0,0000 & 0,0018 & 0,0000 & 0,0044 \\
\hline Всего & 22,0699 & 29,7072 & 0,0409 & 28,1969 & 19,9834 & 0,0000 & 99,9984 \\
\hline \multicolumn{8}{|c|}{ Фракция 170-кк } \\
\hline $\mathrm{C}_{7}$ & 0.0000 & 0.0000 & 0.0028 & 0.0000 & 0.0000 & 0.0000 & 0.0028 \\
\hline $\mathrm{C}_{8}$ & 0.0032 & 0.0000 & 0.0000 & 0.0191 & 0.0730 & 0.0000 & 0.0953 \\
\hline $\mathrm{C}_{9}$ & 1.8772 & 0,3785 & 0,2273 & 4,1332 & 14,1197 & 0,0033 & 20,7392 \\
\hline $\mathrm{C}_{10}$ & 14,5147 & 22,5839 & 0,5639 & 9,8364 & 8,6688 & 4,3127 & 60,4802 \\
\hline
\end{tabular}




\begin{tabular}{|c|c|c|c|c|c|c|c|}
\hline 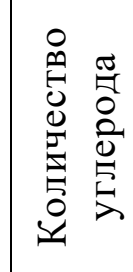 & 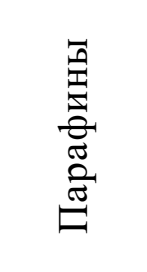 & 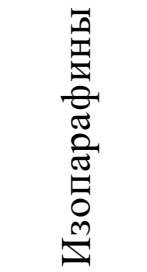 & 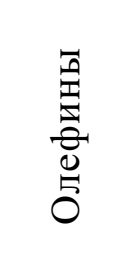 & 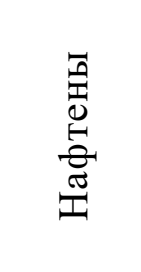 & 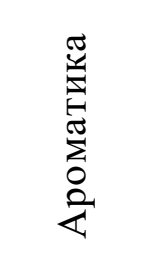 & 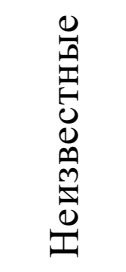 & $\begin{array}{l}0 \\
\dot{0} \\
0 \\
0\end{array}$ \\
\hline $\mathrm{C}_{11}$ & 2,3588 & 10,4988 & 0,0000 & 2,5949 & 2,0460 & 0,0000 & 17,4985 \\
\hline $\mathrm{C}_{12}$ & 0,2853 & 0,1326 & 0,0000 & 0,0000 & 0,4894 & 0,0000 & 0,9072 \\
\hline $\mathrm{C}_{13}$ & 0,0027 & 0,0167 & 0,0006 & 0,0000 & 0,2142 & 0,0000 & 0,2342 \\
\hline $\mathrm{C}_{14}$ & 0,0097 & 0,0000 & 0,0000 & 0,0000 & 0,0250 & 0,0000 & 0,0347 \\
\hline Всего & 19,0515 & 33,6104 & 0,7946 & 16,5836 & 25,6360 & 4,3160 & 95,6761 \\
\hline
\end{tabular}

Полученные значения по результатам анализов группового углеводородного состава вводили в состав моделируемых продуктовых потоков, которые затем смешали для получения сырьевого потока гидрогенизата.

Установка ректификации была смоделирована и откалибрована по режимным параметрам и качеству полученных продуктов. Мнемосхема полученной модели секции 100 представлена на рисунке 2.

В технологической схеме секции 100 пары колонны DT-121 используются как греющий агент ребойлера колонны DT-132, поэтому в колонне DT-121 поддерживается высокое давление для обеспечения движения паров как теплоносителя в системе.

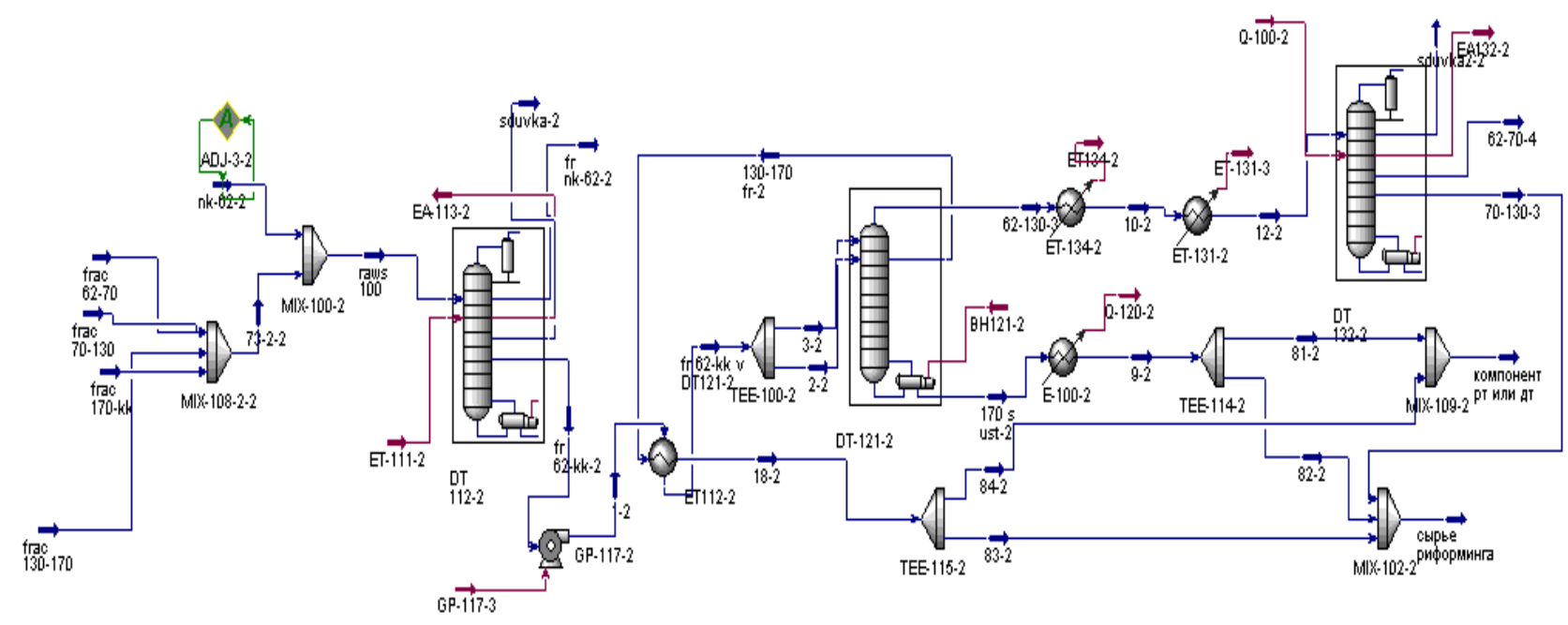

Рисунок 2. Модель секции 100 КПА, выполненная в Aspen Hysys 
При текущей схеме затрачивается большое количество энергии на подогрев куба колонн DT-112, DT-121, DT-132, и соответственно на охлаждение верха данных колонн.

Предлагается модернизировать данную схему, изменив последовательность движения потоков между колоннами.

В таблице 2 представлены режимные параметры колонн при обычной технологической схеме.

В суммарных энергозатратах подвод тепла в куб DT-132 не учитывался, поскольку там используется тепло потока верха DT121.

Из таблицы 2 видно, что большая часть энергетических затрат приходится на первую колонну DT-112 из-за высокого давления и большой подачи орошения. Такой технологический режим обусловлен требованием к высокому содержанию изопентана в дистилляте (фракция нк- $62^{\circ} \mathrm{C}$ ), что приводит к большим затратам энергии на четкое разделение фракций. В колонне DT-121 большой теплоподвод обусловлен высоким давлением $(0,44$ МПа), которое поддерживают для исключения возможности попадания тяжелых углеводородов в сырьё риформинга и движения паров верха как греющего агента.

Таблица 2. Режимные параметры модели секции 100 КПА

\begin{tabular}{|c|c|c|c|c|c|}
\hline \multicolumn{2}{|c|}{ Режимный параметр } & Единица & DT112 & DT121 & DT132 \\
\hline \multirow[t]{5}{*}{ Расход } & Сырьё & \multirow{5}{*}{ Т/ч } & 117,4 & 111,4 & 97,9 \\
\hline & Орошение & & 166 & - & 81,3 \\
\hline & Дистиллят & & 6 & 97,9 & 15 \\
\hline & $\begin{array}{l}\text { Боковой } \\
\text { погон }\end{array}$ & & - & 10 & - \\
\hline & $\begin{array}{l}\text { Кубовый } \\
\text { продукт }\end{array}$ & & 111,4 & 3,5 & 82,9 \\
\hline Давление & Bepx & МПа & 0,23 & 0,44 & 0,05 \\
\hline \multirow{4}{*}{ Температура } & Сырьё & \multirow{4}{*}{${ }^{\circ} \mathrm{C}$} & 116 & 134 & 112 \\
\hline & Bepx & & 53 & 176 & 40 \\
\hline & Орошение & & 50 & - & 40 \\
\hline & Низ & & 127 & 244 & 100 \\
\hline \multicolumn{6}{|c|}{ Затраты энергии } \\
\hline \multicolumn{2}{|c|}{ Теплоподвод в куб колонны } & \multirow{4}{*}{ MBT } & 16,3 & 10,82 & - \\
\hline \multicolumn{2}{|c|}{ Охлаждение верха колонны } & & 15,9 & - & 7,8 \\
\hline \multirow{2}{*}{\multicolumn{2}{|c|}{ Итого }} & & 32,2 & 10,82 & 7,8 \\
\hline & & & \multicolumn{3}{|c|}{50,8} \\
\hline
\end{tabular}


Исходя из этих условий, предложены несколько вариантов изменения последовательности ректификации гидрогенизата для уменьшения затрачиваемого количества энергии при сохранении выхода и качества продуктов. Технологические схемы предлагаемой модернизации представлены на рисунке 3.
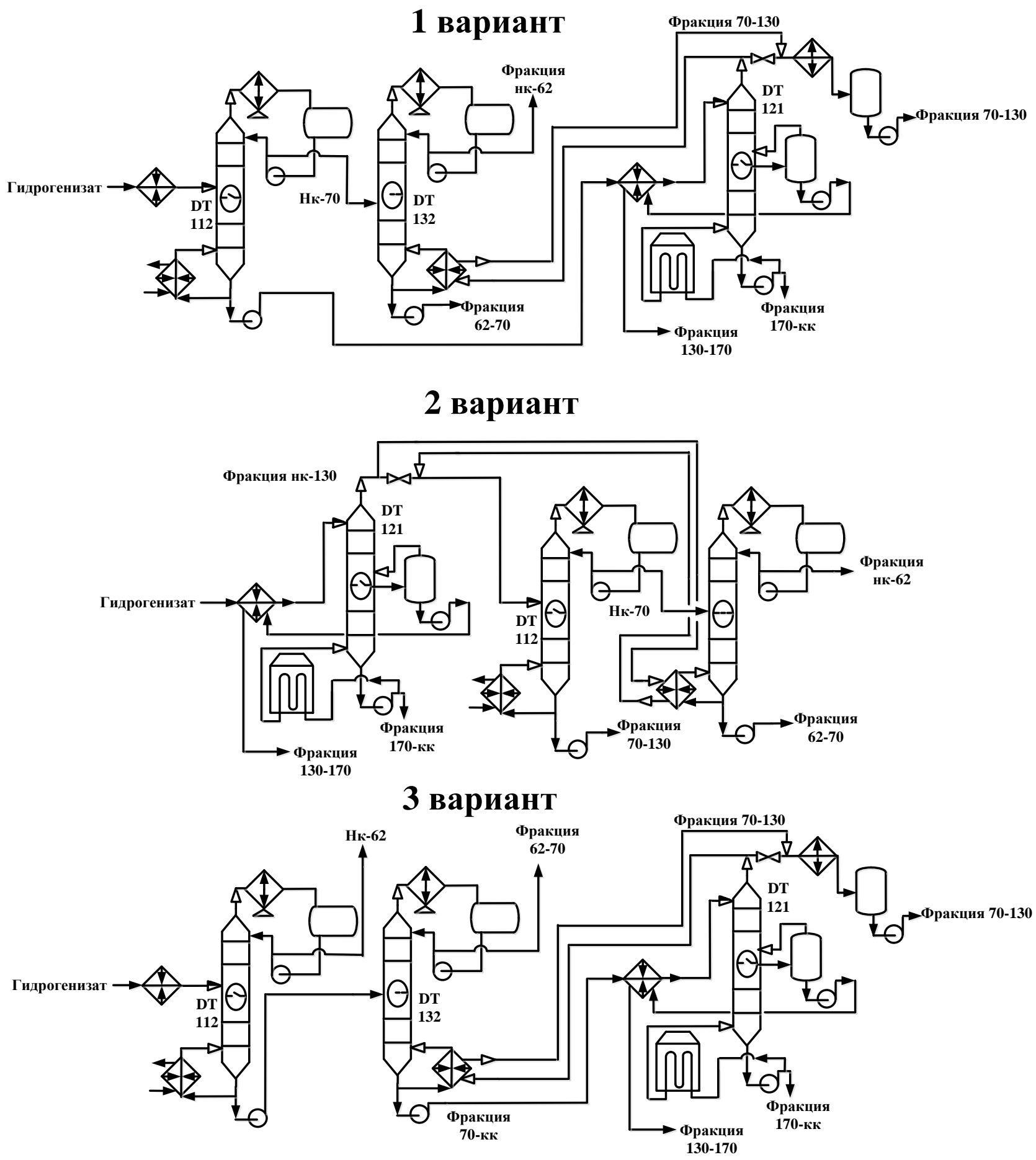

Рисунок 3. Варианты модернизации секции 100 КПА 
В первом предлагаемом варианте гидрогенизат сначала поступает в колонну DT-112, где выделяется фракция нк-70 C при давлении 0,15 МПа. Далее фракция нк- $70^{\circ} \mathrm{C}$ разделяется в колонне DT-132 при давлении 0,12 МПа на фракции нк- $62^{\circ} \mathrm{C}$ и $62-70^{\circ} \mathrm{C}$.

Фракция 70-кк разделяется в колонне DT-121 при давлении 0,35 МПа на фракции $70-130^{\circ} \mathrm{C}, \quad 130-170^{\circ} \mathrm{C}$ и 170 -кк. Такая последовательность ректификации за счет снижения давления в колоннах DT-112 и DT-121 позволяет снизить общие энергозатраты на 20,8 МВт.

Во втором варианте гидрогенизат при давлении 0,35 МПа в DT-121 разделяется на фракции $170-\kappa \kappa, ~ 130-170^{\circ} \mathrm{C}$ и нк- $130^{\circ} \mathrm{C}$. Фракция нк-130 ${ }^{\circ} \mathrm{C}$ сначала отдаёт необходимое количество тепла в ребойлере DT-132, после чего поступает в колонну DT-112, где при давлении 0,12МПа разделяется на фракции $70-130^{\circ} \mathrm{C}$ и нк- $70^{\circ} \mathrm{C}$. Фракция нк- $70^{\circ} \mathrm{C}$ делится в колонне DT-132 при давлении 0,12 МПа на фракции нк- $62^{\circ} \mathrm{C}$ и $62-70^{\circ} \mathrm{C}$. При такой схеме общие энергозатраты снижаются до 29,1 МВт. Увеличение нагрузки колонны DT-121 по сырью приводит к увеличению энергозатрат, однако это компенсируется вводом сырья в DT-112 с большей температурой, что приводит к снижению расхода теплоносителя в ребойлер.

При третьем варианте после колонны DT-112 фракция 62-кк направляется в колонну DT-132, где выделяется фракция 62-70 $\mathrm{C}$, таким образом, уменьшается нагрузка по сырью на DT-121, но растет нагрузка на DT-132. Полученная фракция 70-кк направляется в колонну DT-121, где

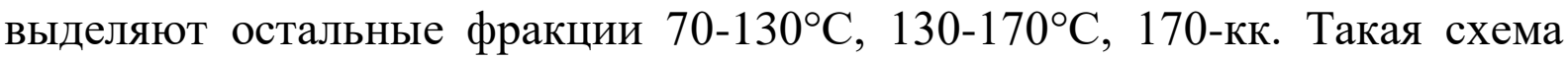
требует на 0,4 МВт меньше энергозатрат, чем при обычном варианте работы секции 100, поэтому такой вариант в перспективе рассматриваться не может.

Результаты расчета энергозатрат представлены в таблице 3 . Модернизация модели текущей технологической схемы выполнялась с сохранением материального баланса и качества потоков. 
Исходя из таблицы 3, можно сделать вывод, что при предлагаемой модернизации (варианты 1,2), основные энергозатраты уменьшаются в колонне DT-112 за счет снятия ограничения по качеству изопентановой фракции, и следовательно снижения давления и расхода орошения из-за увеличения конца кипения дистиллята.

Таблица 3. Режимные параметры секции 100 при различных вариантах модернизации технологической схемы

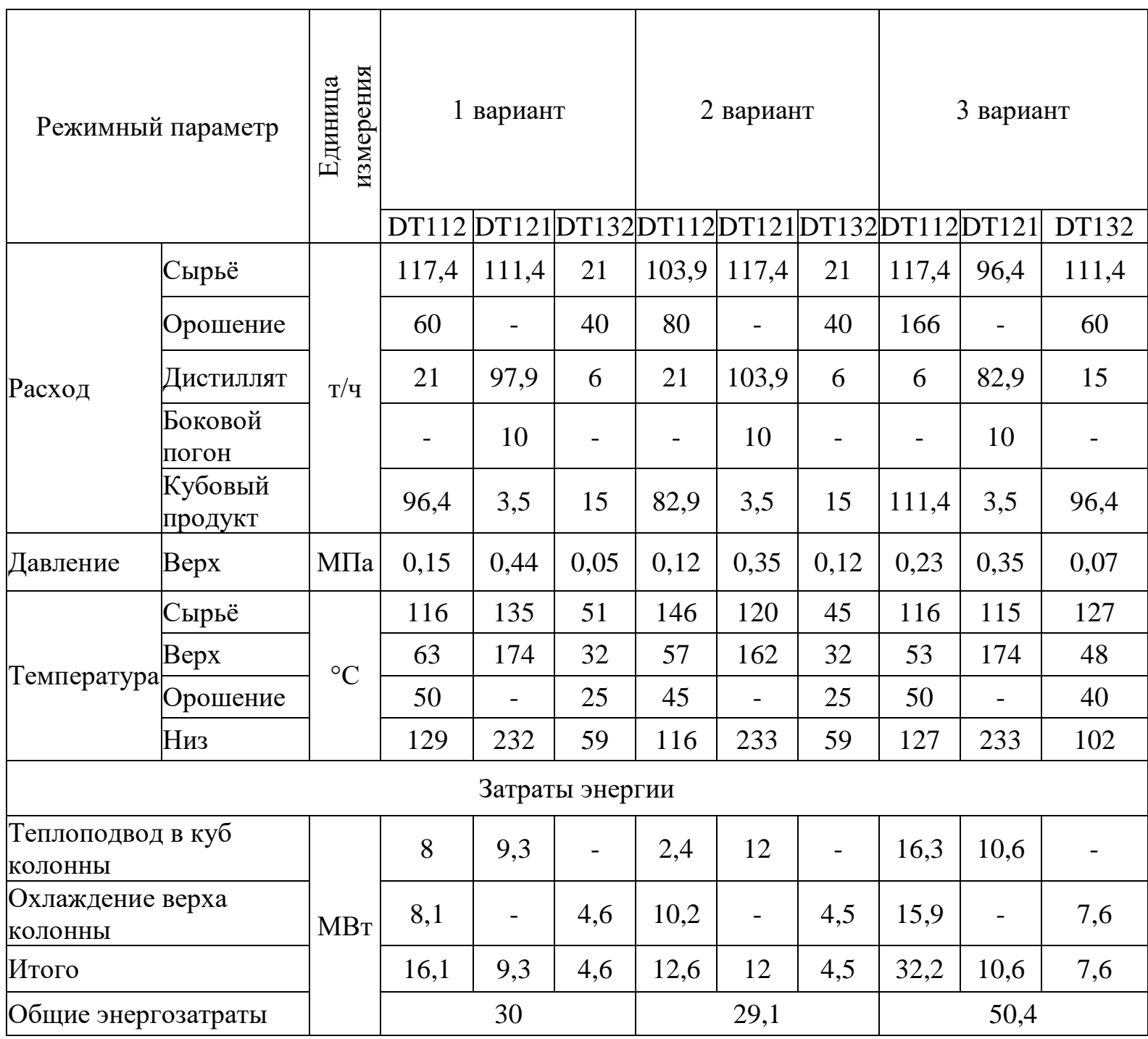

За счет меньшей загрузки колонны DT-132 по сырью происходит более четкое разделения фракций при меньших энергетических нагрузках. Меньшая потребность в нагреве куба колонны DT-132 косвенно снижает необходимую степень нагрева куба колонны DT-121 для обеспечения работоспособности системы передачи тепла парами верха DT-121. 


\section{Выводы}

Предложены два варианта модернизации технологической схемы секции 100 комплекса по производству ароматических углеводородов. Предложенные схемы позволяют разгрузить колонну DT-112 за счет снижения требований к отбираемому дистилляту, а также улучшить качество разделения в колонне DT-132 за счет меньшей загрузке по сырью. Изменение схемы позволяет снизить основные энергетические затраты на обеспечение процесса ректификации с 50,8 до 29-30MBТ при сохранении количества и качества потоков.

Исследование выполнено при финансовой поддержке РФФИ в рамках научного проекта №20-38-90189.

\section{Список используемых источников}

1. Пистер Ф.Ф. Программа энергосбережения предприятия // Нефтепереработка и нефтехимия. Научно-технические достижения и передовой опыт. 2015. № 8. С. 23.

2. Миролимов А.И., Ахадов Ж.3., Мухторов Н.Ш. Опыт энергоэффективности и энергосбережения в промышленности по стандарту ISO 50001 // Агротехника и энергообеспечение. 2018. № 2 (19). С. 67-73.

3. Милюков И.В., Меньшова И.И., Челноков А.В., Юлдашев Х.М. Обеспечения безопасности и конкурентоспособности нефтегазоперерабатывающего комплекса на основе использования энергетического бенч-маркинга // Инновации и инвестиции. 2019. № 3. C. 274-279.

4. Хусаинова Е.К. Совершенствование некоторых составляющих энергоменеджмента для нефтеперерабатывающих предприятий // Казанская наука. 2015. № 6. С. 79-86.

5. Мейерс Р.А. Основные процессы нефтепереработки: справочник / Под ред. О.Ф. Глаголевой, О.П. Лыкова. СПб.: Профессия, 2011. 944 с. 
6. Назарюк В.В., Дюсембаева А.А. Повышение производительности комплекса получения ароматических углеводородов по толуолу // Вестник Омского университета. 2016. № 4 (82). С. 67-69.

7. Гаранин Д.И. Каталитический риформинг бензиновых фракций. Основы теории, эксплуатация и интенсификация процесса. Краснодар: НАФТ, 1996. 90 c.

8. Маслянский Г.Н., Шапиро Р.Н. Каталитический риформинг бензинов: Химия и технология. Л.: Химия, 1985. $221 \mathrm{c.}$

9. Зайнуллин Р.З., Коледина К.Ф., Губайдуллин И.М., Ахметов А.Ф., Коледин С.Н. Кинетическая модель каталитического риформинга бензина с учетом изменения реакционного объема и термодинамических параметров // Кинетика и катализ. 2020. Т. 61. № 4. С. 550-559. DOI: $10.31857 / \mathrm{S} 0453881120040176$.

10. Иванчина Э.Д., Чеканцев Н.В., Чузлов В.А., Смольянова Ю.А. Оптимизация состава углеводородного сырья в процессе изомеризации пентан-гексановой фракции с использованием комплексной математической модели HYSYS - IZOMER // Известия Томского политехнического университета. 2012. Т. 321. № 3. С. 130-132.

\section{References}

1. Pister F.F. Programma energosberezheniya predpriyatiya [Enterprise Energy Saving Program]. Neftepererabotka $i$ neftekhimiya. Nauchnotekhnicheskie dostizheniya i peredovoi opyt-Oil Processing and Petrochemistry, 2015, No. 8, pp. 23. [in Russian].

2. Mirolimov A.I., Akhadov Zh.Z., Mukhtorov N.Sh. Opyt energoeffektivnosti i energosberezheniya $\mathrm{v}$ promyshlennosti po standartu ISO 50001 [Experience of Energy Efficiency and Energy Saving in the Industry Under the Standard ISO 50001]. Agrotekhnika i energoobespechenie - Agrotechnics and Energy Supply, 2018, No. 2 (19), pp. 67-73. [in Russian]. 
3. Milyukov I.V., Menshova I.I., Chelnokov A.V., Yuldashev Kh.M. Obespecheniya bezopasnosti i konkurentosposobnosti neftegazopererabatyvayushchego kompleksa na osnove ispol'zovaniya energeticheskogo bench-markinga [Ensuring the Safety and Competitiveness of the Oil and Gas Processing Complex Through the Use of Energy Bench Markin]. Innovatsii i investitsii - Innovation and Investment, 2019, No. 3, pp. 274-279. [in Russian].

4. Khusainova E.K. Sovershenstvovanie nekotorykh sostavlyayushchikh energomenedzhmenta dlya neftepererabatyvayushchikh predpriyatii [Improvement of Some Elements of Energy Management for Petroleum Refineries]. Kazanskaya nauka - Kazan Science, 2015, No. 6, pp. 79-86. [in Russian].

5. Meiers R.A. Osnovnye protsessy neftepererabotki: spravochnik [Handbook of Petroleum Refining Processes]. Ed. by O.F. Glagolevoi, O.P. Lykova. St. Petersburg, Professiya Publ., 2011. 944 p. [in Russian].

6. Nazaryuk V.V., Dyusembaeva A.A. Povyshenie proizvoditel'nosti kompleksa polucheniya aromaticheskikh uglevodorodov po toluolu [Increased Productivity Toluene on Complex of Aromatic Hydrocarbons]. Vestnik Omskogo universiteta - Herald of Omsk University, 2016, No. 4 (82), pp. 67-69. [in Russian].

7. Garanin D.I. Kataliticheskii riforming benzinovykh fraktsii. Osnovy teorii, ekspluatatsiya $i$ intensifikatsiya protsessa [Catalytic Reforming of Gasoline Fractions. Fundamentals of Theory, Operation and Process Intensification]. Krasnodar, NAFT Publ., 1996. 90 p. [in Russian].

8. Maslyanskii G.N., Shapiro R.N. Kataliticheskii riforming benzinov: Khimiya $i$ tekhnologiya [Catalytic Gasoline Reforming: Chemistry and Technology]. Leningrad, Khimiya Publ., 1985. 221 p. [in Russian].

9. Zainullin R.Z., Koledina K.F., Gubaidullin I.M., Akhmetov A.F., Koledin S.N. Kineticheskaya model' kataliticheskogo riforminga benzina s uchetom izmeneniya reaktsionnogo ob"ema i termodinamicheskikh parametrov [Kinetic Model of Catalytic Gasoline Reforming with Consideration for Changes in the Reaction Volume and Thermodynamic Parameters]. Kinetika i kataliz - Kinetika i Kataliz, 2020, Vol. 61, No. 4, pp. 550-559. DOI: 10.31857/S0453881120040176. [in Russian]. 
10. Ivanchina E.D., Chekantsev N.V., Chuzlov V.A., Smolyanova Yu.A. Optimizatsiya sostava uglevodorodnogo syr'ya v protsesse izomerizatsii pentangeksanovoi fraktsii s ispol'zovaniem kompleksnoi matematicheskoi modeli HYSYS - IZOMER [Optimization of the Composition of Hydrocarbons in the Process of Isomerization of Pentane-Hexane Fraction Using a Complex Mathematical Model HYSYS - IZOMER]. Izvestiya Tomskogo politekhnicheskogo universiteta - Bulletin of the Tomsk Polytechnic University, 2012, Vol. 321, No. 3, pp. 130-132. [in Russian].

\section{Сведения об авторах}

\section{About the authors}

Юсупов Марсель Разифович, аспирант кафедры «Технология нефти и газа», УГНТУ, г. Уфа, Российская Федерация

Marsel R. Yusupov, Post-graduate Student of Oil and Gas Technology Department, USPTU, Ufa, Russian Federation

e-mail: marsel.yusupov.2014@mail.ru

Ганцев Александр Викторович, канд. техн. наук, доцент кафедры «Технология нефти и газа», УГНТУ, г. Уфа, Российская Федерация

Alexander V. Gantsev, Candidate of Engineering Sciences, Assistant Professor of Oil and Gas Technology Department, USPTU, Ufa, Russian Federation

e-mail: a.v.ganzev@yandex.ru 